\title{
HOMENAGEM
}

DOI: http://dx.doi.org/10.20396/sss.v16i2.8651469

(cc) $\mathrm{BY}-\mathrm{NC}-\mathrm{SA}$

\section{RESPEITO E GRATIDÃO À PROFESSORA REGINA MARIA GIFFONI MARSIGUA}

\author{
RESPECT AND GRATITUDE TO THE TEACHER \\ REGINA MARIA GIFFONI MARSIGLIA
}

Edna Maria Goulart Joazeiro ${ }^{1}$

Dalva Rossi ${ }^{2}$

Maria Virgínia Righetti Fernandes Camilo ${ }^{3}$

É com tristeza que realizamos a difícil tarefa de nos despedirmos da assistente social, socióloga, professora, pesquisadora, orientadora, autora, militante da Área da Saúde, Professora Regina Maria Giffoni Marsiglia, que sempre teve como princípio básico de sua vida profissional a socialização do conhecimento que se efetivava nas aulas que ministrava,

\footnotetext{
${ }^{1}$ Assistente social e socióloga, Doutora e Mestre em Educação pela Universidade Estadual de Campinas, PósDoutorado em Serviço Social pelo Programa de Estudos Pós-Graduados da PUC São Paulo, membro do Conselho Editorial e Editora Científica do Periódico Serviço Social \& Saúde. Membro do quadro docente permanente e Chefe do Departamento de Serviço Social da UFPI e docente do Programa de Pós-Graduação em Políticas Públicas da Universidade Federal do Piauí-UFPI. E-mail: emgoulart@uol.com.br.

${ }^{2}$ Doutora pela Faculdade de Ciências Médicas da Universidade Estadual de Campinas e Mestre em Serviço Social pelo Programa de Estudos Pós-Graduados da PUC São Paulo. Membro do Conselho Editorial do Periódico Serviço Social \& Saúde. Assistente social do CAISM UNICAMP e docente do Curso de Serviço Social do Centro Universitário Salesiano de São Paulo, UNISAL. E-mail: dalva.r@ terra.com.br.

${ }^{3}$ Doutora em Educação pela Universidade Estadual de Campinas e Mestre em Serviço Social pelo Programa de Estudos Pós-Graduados da PUC São Paulo, Docente e Diretora da Faculdade de Serviço Social da PUC Campinas. E-mail: chinacamilo@yahoo.com.br.
} 
nas pesquisas realizadas, nos livros produzidos, nas orientações de dissertações e teses, que resultaram em produções acadêmicas valiosas e que contribuem para novos conhecimentos de profissionais e estudantes que buscam o aprimoramento profissional, especialmente na área da política pública de saúde. São muitas as referências sobre essa extraordinária pessoa que nos deixou no mês de julho de 2017 !

A querida professora sempre foi referência profissional na área da saúde, tendo estado presente na formação de intelectuais, na construção do ideário da Reforma Sanitária, participando intensamente dos debates acadêmicos, com profundidade e densidade na pesquisa em saúde, nos congressos não apenas do campo do Serviço Social, e também da Saúde Coletiva. Sempre trouxe para o debate questões que perpassam a profissão, a necessidade de contínua atualização, os desafios da formação em saúde, a necessidade de ampliar o debate no campo.

Acompanhamos sua presença constante como banca em diversas dissertações e teses no Programa de Estudos Pós-Graduados da PUC São Paulo, na Pós Graduação da Faculdade de Educação e na Pós Graduação em Saúde Coletiva, ambos da UNICAMP, sendo o último um dos centros de referência na formação de quadros para a Reforma Sanitária brasileira. Quer seja na sua obra, quer seja nas orientações e nas bancas, seu trabalho significou sempre a abertura de possibilidades, estimulando o aprofundamento do conhecimento, o olhar para a diversidade da produção em saúde e do campo do Serviço Social. Nós que com ela convivemos queremos manifestar nossa imensa gratidão por sua inequívoca contribuição às diversas gerações que acompanhou e incentivou na defesa da Reforma Sanitária.

A preocupação com a área da saúde sempre esteve presente em suas obras e em suas produções científicas, dotadas de rigor acadêmico, com análise fundamentada da relação do Estado com as Políticas Sociais, dentre elas destacava a Saúde e também a defesa de uma formação comprometida com a qualidade e a prestação dos serviços na área da saúde em consonância com os interesses da população que dela se utiliza.

Certamente a Professora Regina, em sua formação e opção profissional, já mantinha o desejo e o interesse em voltar sua atenção, sua especialidade e seus estudos para a área da saúde. Percorreu esse caminho com determinação, buscando continuamente o aprofundamento teórico marcado sempre pelo prazer na partilha desse conhecimento, 
preocupada em atribuir importância às pautas e agendas em diferentes espaços profissionais. O debate, a reflexão e a pesquisa acerca dos desafios postos à política pública de saúde e de seu desenvolvimento, sempre fizeram parte do universo da Professora Regina que, com dedicação, criticidade e responsabilidade ética, provocava questionamentos nos espaços de trabalho, de estudos, de produção de conhecimento e de consolidação da formação de novos profissionais.

Toda gratidão à Professora Regina que durante sua vida profissional se preocupou em socializar o conhecimento, materializado sob a forma de produção científica, de ensino nas salas de aula e fora dela, o que possibilitou a muitos alunos e profissionais a oportunidade de aprofundar e adquirir novos conhecimentos para fundamentar suas ações, bem como construir novas estratégias de ação, particularmente no campo da Saúde.

Queremos ainda destacar o empenho e a contribuição efetiva dos professores que aceitaram participar do Grupo de Trabalho instituído pela Portaria DFCM/ UNICAMP n. ${ }^{\circ}$ 026/2012, que teve como objetivo estudar a criação de Curso de Serviço Social na Faculdade de Ciências Médicas da UNICAMP. O grupo, do qual a professora Regina participou, era composto pelas professoras Edna Maria Goulart Joazeiro (UNICAMP), Dalva Rossi (UNICAMP), Tânia Maria Granzotto (UNICAMP), Maria Lúcia Martinelli (PUC São Paulo), Cesar Nunes (UNICAMP), Maria Carmelita Yazbek (PUC São Paulo), Regina Maria Giffoni Marsiglia (PUC São Paulo e Santa Casa de Misericórdia de São Paulo), Maria Liduína de Oliveira e Silva (UNIFESP) e Cláudia Mônica dos Santos (UFJF, MG), o trabalho realizou-se sob a presidência da primeira, predominantemente, no campus da UNICAMP, na cidade de Campinas.

A dinâmica instaurada implicou na necessidade de contínuos deslocamentos das professoras provenientes da capital do Estado de São Paulo, da cidade de Santos e de Juiz de Fora, Minas Gerais. Cumpre destacar e agradecer a todos os participantes que, a despeito da distância, do dispêndio de energia e de tempo, não pouparam esforços para estarem presentes nas reuniões de trabalho, tendo contado com a primorosa participação de todos e de cada um na produção do documento intitulado "Relatório do Estudo do Projeto de Criação de Curso de Bacharelado em Serviço Social da Faculdade de Ciências Médicas - Universidade Estadual de Campinas, UNICAMP” (2013, 86 f). O ousado e primoroso estudo que propunha a criação do Curso de Serviço Social para a UNICAMP não logrou tornar-se realidade até o 
presente momento, contudo o projeto expressa o anseio e a necessidade da criação de um curso de Serviço Social voltado para a realidade regional e local dessa importante região do Estado de São Paulo, na Universidade Estadual de Campinas. Na manifestação de gratidão ora explicitada, almejamos rememorar fatos, e de forma breve, resgatar a história da vida profissional da professora Regina e de um coletivo de profissionais pelos quais nutrimos um grande carinho e respeito, em função da contribuição pelos conhecimentos partilhados no decorrer da história.

Por último, nessa singela homenagem à Prof. ${ }^{a}$ Regina, autora e colega do Conselho Científico do periódico Serviço Social \& Saúde, queremos destacar a importância de sua participação na história deste periódico desde o dia 07 de setembro de 2009, ocasião em que confirmou seu aceite a nosso convite na mensagem eletrônica que se segue: "a Revista está tomando um vulto que não se imaginava quando de seu início. Se persistir por aí, daqui a algum tempo poderá entrar no sistema de Classificação da Capes e CNPq. Confirmo meu aceite para participar do Conselho Editorial".

Nós, membros do Conselho Editorial e do Conselho Científico do periódico Serviço Social \& Saúde tivemos o orgulho de trabalhar juntos com a professora Regina nestes quase oito anos, no qual produzimos 16 exemplares da Revista consolidando assim o anseio da professora expresso quando do aceite para compor o Conselho Científico da Revista. Neste vigésimo quarto exemplar da Revista, - décimo sétimo publicado na constância da participação da Professora na nossa Equipe - nos coube a triste, mas honrosa tarefa de fazer essa despedida, mais do que isto, de celebrar a sua vida, sua história, suas conquistas tanto no campo do Serviço Social, quanto no campo da Saúde pública. E é essa crença na importância do coletivo que queremos destacar lançando mão das palavras da professora Regina, de seu ponto de vista expresso na Entrevista que concedeu a Equipe deste periódico, quando indagada sobre os desafios postos ao Serviço Social na atualidade (no segundo semestre de 2012) a mesma assinalou que,

[...] o Serviço Social precisa se apropriar urgentemente da produção da Saúde Coletiva, dialogar com ela e participar do avanço do conhecimento sobre os determinantes sociais do processo saúde-doença. Transformar sua experiência e observação, muito importante sobre a realidade social e suas interfaces com a saúde, em uma produção sistemática de conhecimento, que possa subsidiar a análise não só da profissão internamente, mas das demais profissões que participam da área de saúde. Outro desafio é produzirmos um 
conhecimento que contemple as particularidades de nossa formação social, com os necessários recortes regionais e institucionais. [finaliza sua reflexão afirmando que o êxito na luta pela garantia dos direitos dos usuários ao acesso aos serviços] depende muito, em primeiro lugar da organização da população, e, de nossa capacidade de conseguirmos aliados nas outras profissões para essa mesma luta (MARSIGLIA, 2013, p 133-134).

Campinas, 24 de dezembro de 2017.

Edna Maria Goulart Joazeiro

Dalva Rossi

Maria Virginia Righetti Fernandes Camilo

Recebido em 24.12.2017 - Aprovado em 26.12.2017

Serv. Soc. \& Saúde, Campinas, SP v.16, n. 2 (24), p. 305-310, jul./dez. 2017 E-ISSN 2446-5992 
